\title{
Magnetostrictive and Shape Memory Properties of Heusler Type $\mathrm{Co}_{2} \mathrm{NiGa}_{\mathrm{Alloys}}{ }^{* 1}$
}

\author{
Mitsutaka Sato $^{1, * 2}$, Teiko Okazaki ${ }^{1}$, Yasubumi Furuya ${ }^{1}$ and Manfred Wuttig ${ }^{2}$ \\ ${ }^{1}$ Faculty of Science and Technology, Hirosaki University, Hirosaki 036-8561, Japan \\ ${ }^{2}$ Department of Materials and Nuclear Engineering, University of Maryland, College Park, MD 20742-2115, USA
}

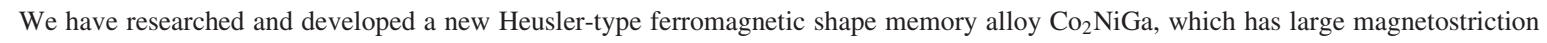
caused by the magnetic-field-induced re-arrangement of martensite twin. The ribbon samples produced by rapid-solidification melt-spinning method show strong texture and large magnetostriction $\varepsilon$ of about $110 \times 10^{-6}$ for an applied magnetic field of $800 \mathrm{kA} \cdot \mathrm{m}^{-1}$ at room temperature. When increasing temperature, the martensite phase of $\mathrm{Co}_{52.4} \mathrm{Ni}_{22} \mathrm{Ga}_{25.6}$ and $\mathrm{Co}_{52.1} \mathrm{Ni}_{26.1} \mathrm{Ga}_{21.8}$ ribbons disappears at about $390 \mathrm{~K}$ and $330 \mathrm{~K}$, respectively, where the drastic shape recovery arises. Some of the ribbons have good ductility and are not broken even after bending to an angle of $180^{\circ}$, indicating that the $\mathrm{Co}_{2} \mathrm{NiGa}$ system has a possibility of new ferromagnetic shape memory material with good ductility.

(Received September 3, 2002; Accepted January 17, 2003)

Keywords: $\mathrm{Co}_{2} \mathrm{NiGa}$ system, ferromagnetic shape memory alloy, martensite phase, magnetostriction, rapid solidification, shape memory effect

\section{Introduction}

A ferromagnetic shape memory alloy (FSMA) is expected to be useful as a new type actuator/sensor material having a nature of magnetostriction with a quick response. Recently, it has been reported that ferromagnetic single crystals of $\mathrm{Ni}_{2} \mathrm{MnGa},{ }^{1)} \mathrm{Fe}-\mathrm{Pd}^{2)}$ and $\mathrm{Fe}-\mathrm{Pt}^{3)}$ show a few $\%$ strains caused by the rearrangement of martensite variants. However, in spite of their exceedingly huge strain, these alloys have serious weaknesses, that is, working to fiber or foil is very difficult because of the poor ductility or their low martensite transformation temperatures.

In a previous study, ${ }^{4)}$ we showed that polycrystalline $\mathrm{Fe}-$ $29.6 \%$ Pd ribbons prepared by rapid-solidification melt-spinning method have fine columnar microstructure with strong oriented texture, giant magnetostriction of 1000-1800 $\times$ $10^{-6}$ and good shape memory effect.

It has been claimed that the martensite-phase starting temperature $\mathrm{Ms}$ for the Heusler type $\mathrm{Ni}_{2} \mathrm{MnGa}$ alloy depends on the valence-electron concentration. ${ }^{5)}$ According to this relation, Wuttig et al. suggested that $\mathrm{CoNiGa}$ system has a possibility of FSMA. ${ }^{6)}$ In order to develop a new FSMA of $\mathrm{Co}_{2} \mathrm{NiGa}$ alloy, we controlled both $\mathrm{Ga}$ and $\mathrm{Ni}$ concentrations so as to let Ms be in temperature from 150 to $400 \mathrm{~K}$. This temperature range is necessary to put actuator/sensor material to practical use. Next, we prepared the thin ribbon samples by using the rapid-solidification melt-spinning method to get fine columnar microstructure with strong oriented texture, and investigated the crystal structure, magnetic properties, magnetic field induced strain, martensite transformation temperatures and shape memory effect.

\section{Experimental Procedure}

Ingots of $\quad \mathrm{Co}_{50.3} \mathrm{Ni}_{23.2} \mathrm{Ga}_{26.5}, \quad \mathrm{Co}_{51} \mathrm{Ni}_{22.9} \mathrm{Ga}_{26.1}$, $\mathrm{Co}_{52.4} \mathrm{Ni}_{22} \mathrm{Ga}_{25.6}$ and $\mathrm{Co}_{52.1} \mathrm{Ni}_{26.1} \mathrm{Ga}_{21.8}$ alloys were prepared from cobalt (99.9\%), nickel (99.9\%), and gallium (99.999\%) metals by using arc-melting method in an argon atmosphere.

\footnotetext{
*1This Paper was Partially Originally Published in J. Japan Inst. Metals. 66 (2002) 147-150.

${ }^{* 2}$ Graduate Student, Hirosaki University.
}

The composition of these ribbons described above was checked by using Electro Probe Micro Analyzer (EPMA). The bulk samples (plate with $1 \mathrm{~mm}$ thickness) were obtained by cutting each ingot. The ribbon samples with $60 \mu \mathrm{m}$ thickness were produced from the alloy ingot by using an originally designed single-rolled melt-spinning apparatus ${ }^{4)}$ with iron wheel in an argon atmosphere. The X-ray diffraction (XRD) was measured for ribbon and bulk samples by using $\mathrm{Cu}-K_{\alpha}$ radiation. The appearance and disappearance of thermoelastic martensite twins were observed by a laser microscope (Lasertec 1LM21) during heating and cooling processes between $293 \mathrm{~K}$ and $473 \mathrm{~K}$. A bend-ductility test was done by bending the samples one by one from $0^{\circ}$ to $180^{\circ}$. The magnetization $M$ vs. applied magnetic field $H$ loop was measured by vibrating samples magnetometer (VSM) method. The magnetostriction $\varepsilon$ was measured by a strain-gauge attached to the sample surface (see Fig. 5(b)). The samples were set in a furnace between the electromagnets. The shape memory effect was evaluated from the observation of shape recovery of the curled ribbons in silicone oil during heating.

\section{Results and Discussion}

\subsection{Surface observation and crystal structure analysis of ribbon samples}

As shown in Fig. 1, the cross-section of the $\mathrm{Co}_{52.4} \mathrm{Ni}_{22} \mathrm{Ga}_{25.6}$ ribbon is found to exhibit fine columnar microstructure with about $20 \mu \mathrm{m}$ in width as has been observed for a rapidly solidified Fe-29.6 at\%Pd ribbon. ${ }^{4}$

Figure 2 shows laser microscopic photographs of the $\mathrm{Co}_{52.4} \mathrm{Ni}_{22} \mathrm{Ga}_{25.6}$ ribbon surface during heating and cooling. As seen in Fig. 2, grain size of the ribbon is $10-30 \mu \mathrm{m}$. This corresponds to the columnar microstructure size as shown in Fig. 1. The martensitic stripe-pattern appears in the grain. When increasing temperature from $296 \mathrm{~K}$ (heating process), the pattern was clearly observed up to $368 \mathrm{~K}$, but almost disappeared at $393 \mathrm{~K}$. When decreasing temperature from $393 \mathrm{~K}$ (cooling process), the martensitic stripe-pattern reappeared at $355 \mathrm{~K}$. The similar behavior was observed for the $\mathrm{Co}_{52.1} \mathrm{Ni}_{26.1} \mathrm{Ga}_{21.8}$ ribbon. On the other hand, the pattern was not observed for the $\mathrm{Co}_{50.3} \mathrm{Ni}_{23.2} \mathrm{Ga}_{26.5}$ ribbon and bulk samples. 


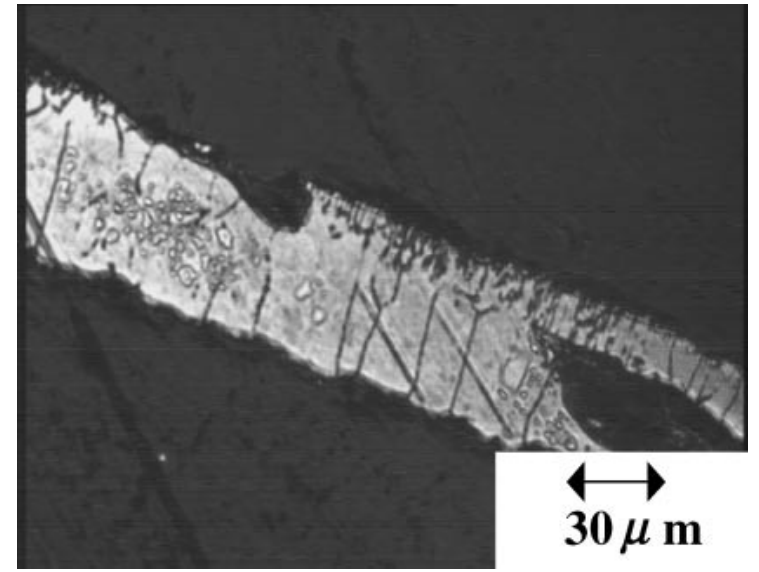

Fig. 1 Cross section observation of a $\mathrm{Co}_{52.4} \mathrm{Ni}_{22} \mathrm{Ga}_{25.6}$ ribbon.

Figure 3(a) shows XRD patterns on $\mathrm{Co}_{52.4} \mathrm{Ni}_{22} \mathrm{Ga}_{25.6}$ ribbon and bulk samples. The XRD peaks are very weak to be observed, except a few peaks for bulk. On the other hand, for ribbon which has martensite phase $(\mathrm{M})$ as seen in Fig. 2, $101_{\mathrm{M}}, 011_{\mathrm{M}}, 110_{\mathrm{M}}, 200_{\mathrm{M}}, 210_{\mathrm{M}}, 211_{\mathrm{M}}$ etc. peaks are clearly seen. Moreover, there appear $220_{\mathrm{A}}$ and $511_{\mathrm{A}}$ peaks due to austenite (A). Martensite and austenite contributions cannot be resolved completely. Since the peak at about $2 \theta=43^{\circ}$ is strong and split into two peaks, $101_{\mathrm{M}}\left(010_{\mathrm{M}}\right)$ and $110_{\mathrm{M}}$, it can be concluded that the ribbon has strong crystalline anisotropic texture and tetragonal martensite phase. ${ }^{6)}$ After annealing for $100 \mathrm{~h}$ at $693 \mathrm{~K}$ in order to remove internal stress caused by rapid-solidification method, $200_{M}+400_{A}$ and $002_{\mathrm{M}}$ peaks are clearly seen as shown in Fig. 3(b). From the results, it is expected that the ribbon sample consists of a martensitic body-centered tetragonal structure (bct) with lattice constants, $a=0.286 \mathrm{~nm}$ and $c=0.297 \mathrm{~nm}$.

From the XRD experiments, it was found that the $\mathrm{Co}_{52.1} \mathrm{Ni}_{26.1} \mathrm{Ga}_{21.8}$ ribbon consists of a martensitic tetragonal structure only, and the greater part of the $\mathrm{Co}_{50.3} \mathrm{Ni}_{23.2} \mathrm{Ga}_{26.5}$ ribbon have an fcc structure with $a=0.359 \mathrm{~nm}$ and the remainder martensitic bct structure. The composition of these alloys corresponds to the $\beta+\gamma$ two-phase region in the CoNi-Ga ternary system. ${ }^{7)}$

\subsection{Bend-ductility test}

Ductility for the four ribbon samples was investigated in order to compare with the brittleness of $\mathrm{Ni}_{2} \mathrm{MnGa}$ system alloy. The results of bend-ductility test are listed in Table 1, where symbols $\bigcirc$ and $\times$ denote unbroken and broken, respectively. The $\mathrm{Co}_{50.3} \mathrm{Ni}_{23.2} \mathrm{Ga}_{26.5}$ ribbon doesn't break even for bending angle of $180^{\circ}$, because it consists of both fcc and martensite structures. ${ }^{7)}$ As increasing Co concentration,

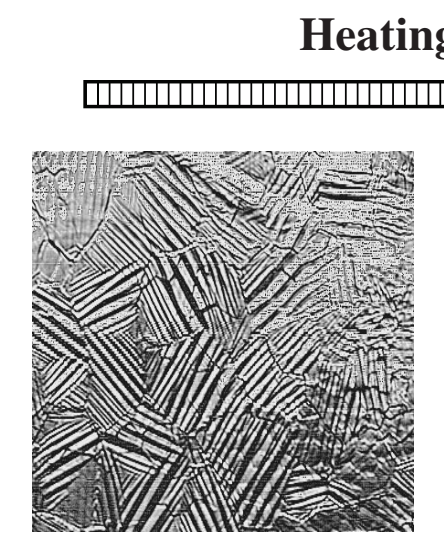

296K

$303 \mathrm{~K}$

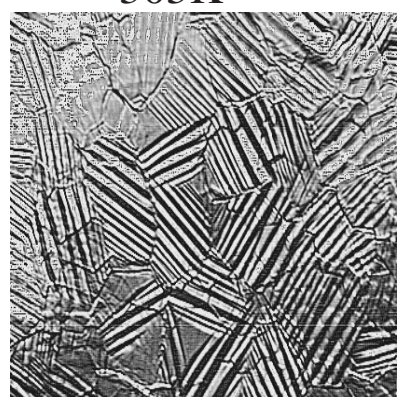

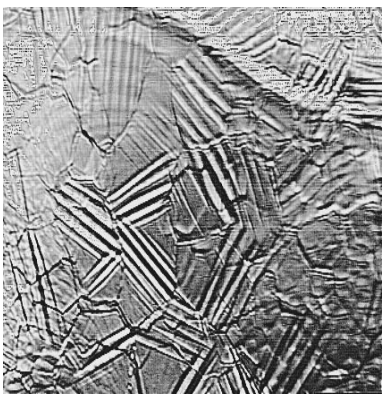

$368 \mathrm{~K}$

$355 \mathrm{~K}$

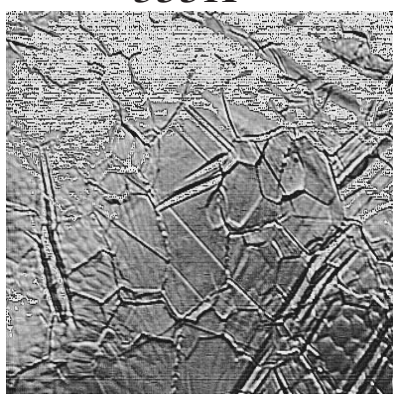

$\mathrm{Co}_{52.4} \mathrm{Ni}_{22} \mathrm{Ga}_{25.6}$

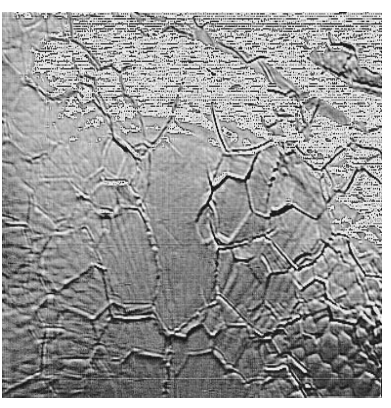

$393 \mathrm{~K}$

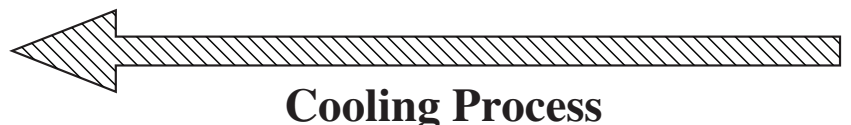

\section{Cooling Process}

Fig. 2 Surface observation of the $\mathrm{Co}_{52.4} \mathrm{Ni}_{22} \mathrm{Ga}_{25.6}$ ribbon on heating and cooling processes. 


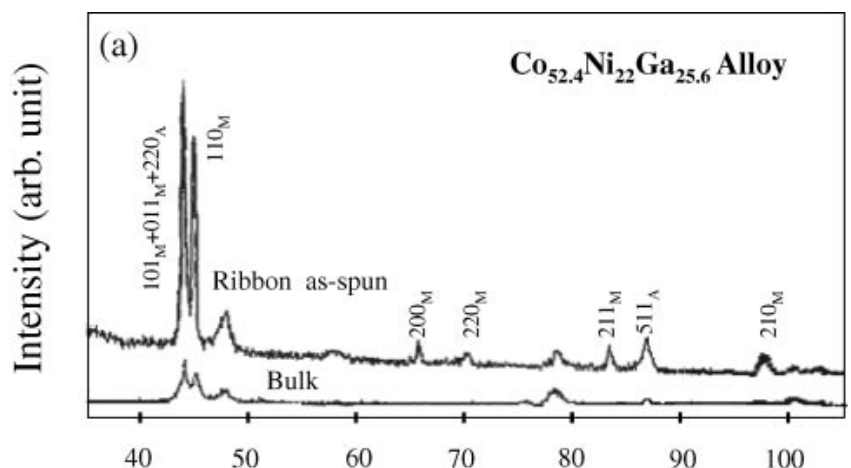

Scattering Angle, $2 \theta$ /degree

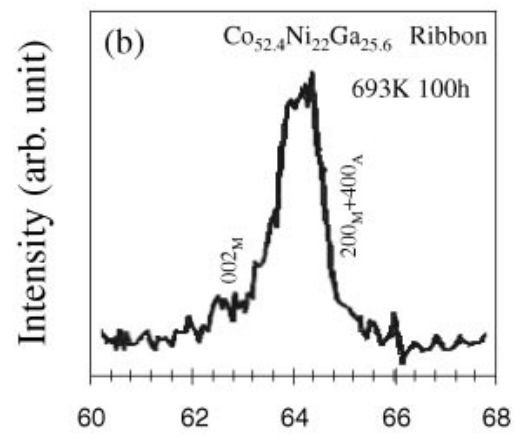

Scattering Angle, $2 \theta$ /degree

Fig. 3 X-ray diffraction profiles of (a) a $\mathrm{Co}_{52.4} \mathrm{Ni}_{22} \mathrm{Ga}_{25.6}$ ribbon and the bulk samples and (b) the $\mathrm{Co}_{52.4} \mathrm{Ni}_{22} \mathrm{Ga}_{25.6}$ ribbon annealed for $100 \mathrm{~h}$ at $693 \mathrm{~K}$.

Table 1 Bend-ductility test of four ribbons, where symbols $\bigcirc$ and $\times$ denote unbroken and broken, respectively.

\begin{tabular}{ccccccccc}
\hline $\begin{array}{c}\text { Bending angle } \\
\phi\end{array}$ & $0^{\circ}$ & $20^{\circ}$ & $40^{\circ}$ & $70^{\circ}$ & $80^{\circ}$ & $120^{\circ}$ & $170^{\circ}$ & $180^{\circ}$ \\
\hline $\mathrm{Co}_{50.3} \mathrm{Ni}_{23.2} \mathrm{Ga}_{26.5}$ & $\bigcirc$ & $\bigcirc$ & $\bigcirc$ & $\bigcirc$ & $\bigcirc$ & $\bigcirc$ & $\bigcirc$ & $\bigcirc$ \\
\hline $\mathrm{Co}_{51} \mathrm{Ni}_{22.9} \mathrm{Ga}_{26.1}$ & $\bigcirc$ & $\bigcirc$ & $\bigcirc$ & $\bigcirc$ & $\bigcirc$ & $\bigcirc$ & $\bigcirc$ & $\times$ \\
\hline $\mathrm{Co}_{52.4} \mathrm{Ni}_{22} \mathrm{Ga}_{25.6}$ & $\bigcirc$ & $\bigcirc$ & $\bigcirc$ & $\bigcirc$ & $\times$ & $\times$ & $\times$ & $\times$ \\
\hline $\mathrm{Co}_{52.1} \mathrm{Ni}_{26.1} \mathrm{Ga}_{21.8}$ & $\bigcirc$ & $\times$ & $\times$ & $\times$ & $\times$ & $\times$ & $\times$ & $\times$ \\
\hline
\end{tabular}

the structure of ribbon becomes purely of martensite and therefore the ribbon becomes brittle. From these results, $\mathrm{Co}_{2} \mathrm{NiGa}$ system alloy dose not have the difficulty of brittleness in working to shape in contrast to the case of $\mathrm{Ni}_{2} \mathrm{MnGa}$ system alloy.

\subsection{Magnetic property}

Figure 4(a) shows the $M$ vs. $H$ loops of the $\mathrm{Co}_{52.4} \mathrm{Ni}_{22} \mathrm{Ga}_{25.6}$ ribbon and (b) a schematic diagram of measurement arrangement. The sample can be rotated around the rolling direction and the magnetic field was applied perpendicular to the rolling direction (RD). Angle $\theta$ of sample rotated around the RD is defined as an angle between the transverse direction of ribbon and magnetic field, as seen in Fig. 4(b). The magnetization $M$ for $\theta=0^{\circ}$ was saturated at $H=400 \mathrm{kA} \cdot \mathrm{m}^{-1}$ and has small coercive force, $H c$ of $5.44 \mathrm{kAm}^{-1}$. The saturation magnetization, $47.73 \times$ $10^{-6} \mathrm{~Wb} \cdot \mathrm{m} \cdot \mathrm{kg}^{-1}$ at $H=800 \mathrm{kA} \cdot \mathrm{m}^{-1}$ was nearly equal to

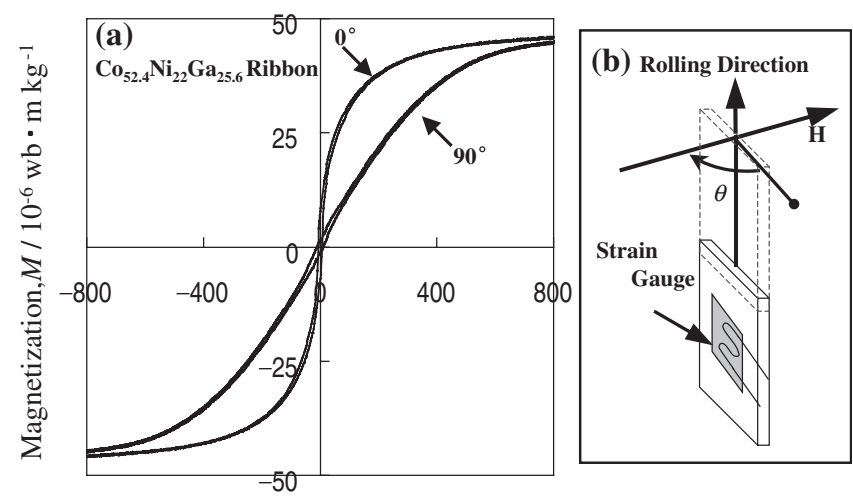

Applied Magnetic Field, $H / \mathrm{kA} \mathrm{m}^{-1}$

Fig. 4 (a) Direction dependence of magnetization of the $\mathrm{Co}_{52.4} \mathrm{Ni}_{22} \mathrm{Ga}_{25.6}$ ribbon sample, and (b) schematic diagram of measurement method.

that of bulk. On the other hand, the $M$ for $\theta=90^{\circ}$ was not saturated still at $H=800 \mathrm{kA} \cdot \mathrm{m}^{-1}$ because of the induced large demagnetic field due to the very thin shape of ribbon sample, and has larger coercive force than that for $\theta=0^{\circ}$. In short, the ribbon sample has magnetically anisotropic texture. The bulk sample exhibits $M$ vs. $H$ loops similar to that of the ribbon, but the coercive force is smaller. The similar results were also obtained for the $\mathrm{Co}_{50.3} \mathrm{Ni}_{23.2} \mathrm{Ga}_{26.5}$ and $\mathrm{Co}_{52.1} \mathrm{Ni}_{26.1} \mathrm{Ga}_{21.8}$ ribbons. The $\mathrm{Ni}_{2} \mathrm{MnGa}$ alloy needs appropriate heat treatment in order to obtain a large magnetization, but $\mathrm{Co}_{2} \mathrm{NiGa}$ system alloys have large magnetization at room temperature without any heat treatment.

Figure 5 shows the direction dependence of coercive force of ribbon and bulk samples. The coercive force of $\mathrm{Co}_{50.3} \mathrm{Ni}_{23.2} \mathrm{Ga}_{26.5}, \mathrm{Co}_{52.4} \mathrm{Ni}_{22} \mathrm{Ga}_{25.6}$ and $\mathrm{Co}_{52.1} \mathrm{Ni}_{26.1} \mathrm{Ga}_{21.8}$ ribbons depends remarkably on $\theta$ and has maximum at $\theta=70^{\circ}-80^{\circ}$. It can be considered that this anisotropy originates from the strong texture that consists of columnar microstructure caused by the rapid solidification. On the other hand, the coercive force of the bulk depends scarcely on $\theta$, indicating magnetically isotropic texture for bulk. Figure 6 shows the temperature dependence of the maximum coercive force for three ribbons, obtained from $M-H$ loops. When increasing temperature, the coercive force of $\mathrm{Co}_{52.4} \mathrm{Ni}_{22} \mathrm{Ga}_{25.6}$ ribbon rapidly decreases between $350 \mathrm{~K}$

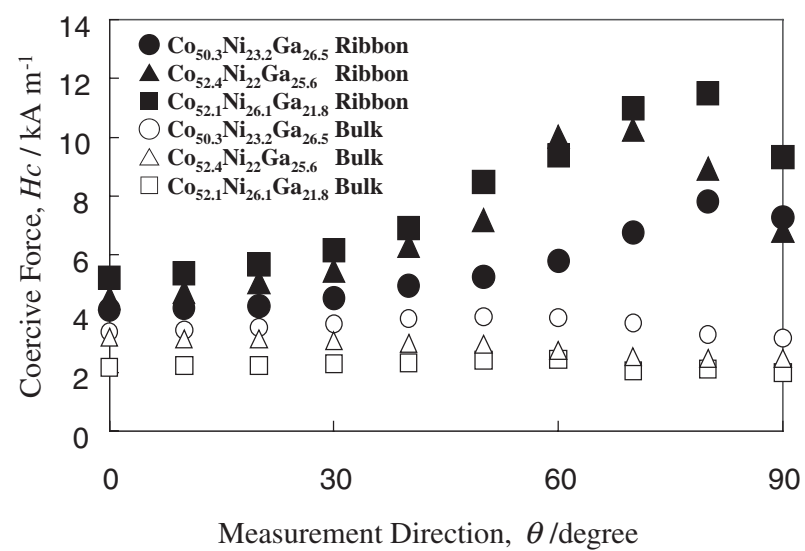

Fig. 5 Direction dependence of coercive force of the bulk and ribbon samples. 


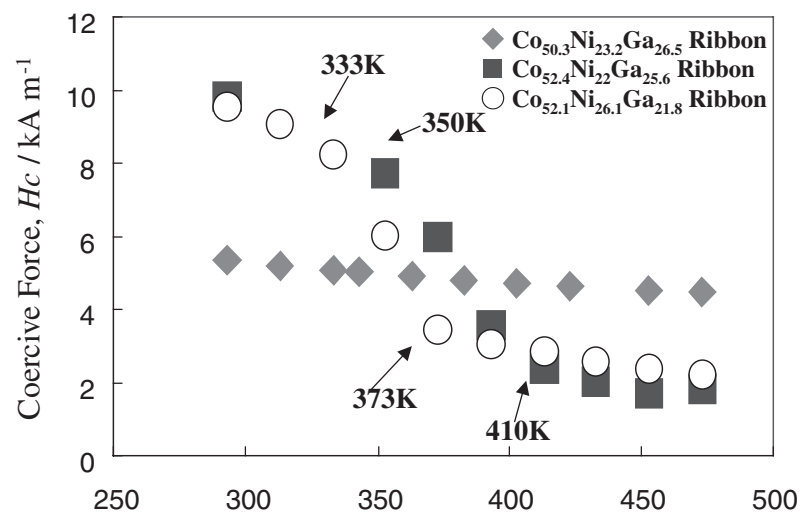

Temperature, $T$ / K

Fig. 6 Temperature dependence of coercive force of the three ribbons.

and $410 \mathrm{~K}$. The $\mathrm{Co}_{52.1} \mathrm{Ni}_{26.1} \mathrm{Ga}_{21.8}$ ribbon also decreases at temperatures between $333 \mathrm{~K}$ and $373 \mathrm{~K}$. This phenomenon occurs when the specimen becomes magnetically isotropic, which is accompanied with the phase change to austenite. On the other hand, the coercive force of $\mathrm{Co}_{50.3} \mathrm{Ni}_{23.2} \mathrm{Ga}_{26.5}$ ribbon does not change in the same temperature range of this measurement.

\subsection{Magnetostriction}

Figure 7 shows magnetostriction $\varepsilon-H$ curves for $\mathrm{Co}_{52.4} \mathrm{Ni}_{22} \mathrm{Ga}_{25.6}$ (a) ribbon and (b) bulk samples. Magnetostriction of ribbon depends on $\theta$ remarkably and exhibits a maximum value of $-110 \times 10^{-6}$ at $\theta=60^{\circ}$ possibly due to the strong oriented texture of the sample. On the other hand, $\varepsilon$ of bulk in randomly oriented polycrystal has a maximum of $-30 \times 10^{-6}$ at $\theta=0^{\circ}$ and is saturated at $H=450 \mathrm{kA} \cdot \mathrm{m}^{-1}$. These results show that the magnetostriction of ribbon sample becomes 3.5 times larger than that of bulk. It can be considered that the enhancement of $\varepsilon$ for ribbon is due to strong texture which consists of a fine columnar microstructure parallel to the thickness direction of ribbon film prepared by rapid solidification. The magnetostrictions of $\mathrm{Co}_{50.3} \mathrm{Ni}_{23.2} \mathrm{Ga}_{26.5}$ and $\mathrm{Co}_{52.1} \mathrm{Ni}_{26.1} \mathrm{Ga}_{21.8}$ ribbons are smaller than that of the $\mathrm{Co}_{52.4} \mathrm{Ni}_{22} \mathrm{Ga}_{25.6}$.

Figure 8 shows the temperature dependence of magnetos-
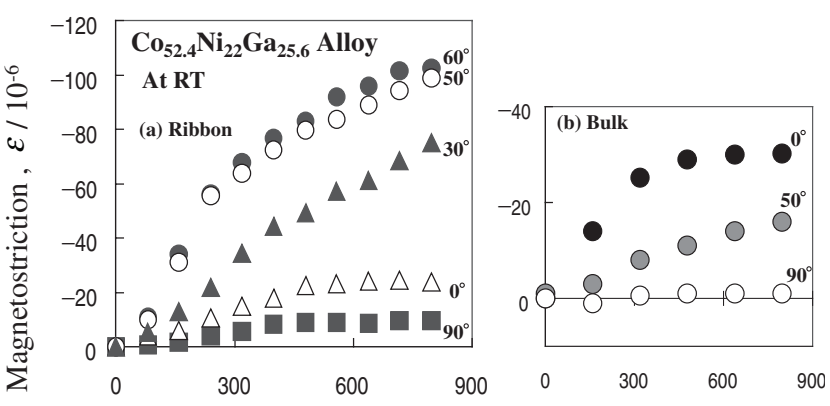

Applied Magnetic Field, $H / \mathrm{kA} \mathrm{m}^{-1}$

Fig. 7 Direction dependence of magnetostriction measured at room temperature of (a) ribbon sample, and (b) bulk samples for $\mathrm{Co}_{52.4} \mathrm{Ni}_{22} \mathrm{Ga}_{25.6}$.

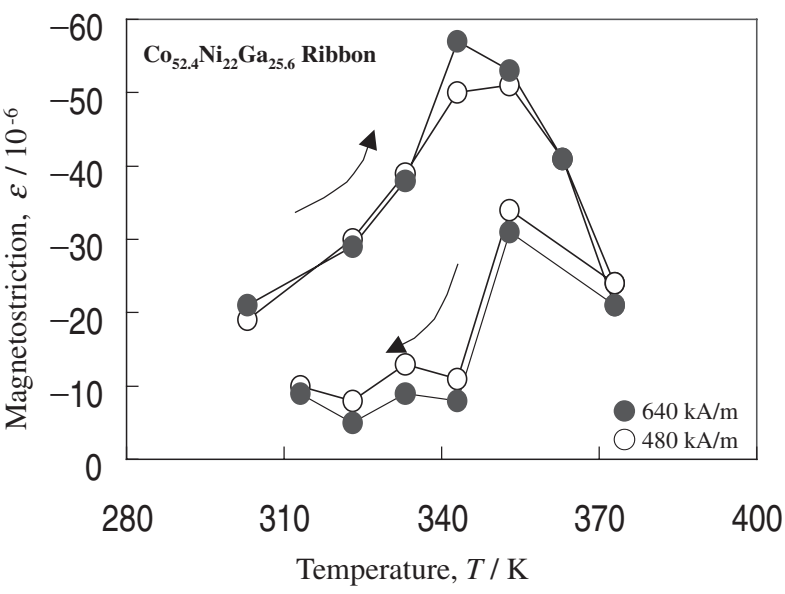

Fig. 8 Magnetostriction $\varepsilon$ vs. $T$ curves for the $\mathrm{Co}_{52.4} \mathrm{Ni}_{22} \mathrm{Ga}_{25.6}$ ribbon.

triction $\varepsilon$ of the $\mathrm{Co}_{52.4} \mathrm{Ni}_{22} \mathrm{Ga}_{25.6}$ ribbon. When increasing temperature, the $\varepsilon$ first increases and reaches a maximum at $340 \mathrm{~K}$, and then decreases rapidly to a value at $370 \mathrm{~K}$. Inversely when decreasing temperature, the $\varepsilon$ increases again and reaches a maximum at $353 \mathrm{~K}$, and then decreases to the bottom value at $340 \mathrm{~K}$. From the result, we conclude that the magnetostriction is caused by rearrangements of the martensite twin variants activated in the temperature range below the austenite-phase starting temperature $A_{\mathrm{s}}$.

\subsection{Shape memory effect and the reverse transforma- tion temperatures}

Figure 9(a) shows a temperature dependence of shape recovery ratio $\left(\phi_{\mathrm{T}} / \phi_{0}\right)$ of the three ribbon samples, where $\phi_{0}$ and $\phi_{\mathrm{T}}$ are radii of curled ribbon at room temperature and $T$ K, respectively (see Fig. 9(b)). The ratio of 6-6.5 means perfect recovery, that is larger than that of $\mathrm{Co}-25$ at $\% \mathrm{Ni}-$ 30 at $\% \mathrm{Ga}^{7)}$ Drastic shape recovery arises in the temperature ranges of $373-418 \mathrm{~K}$ and $338-368 \mathrm{~K}$, respectively for $\mathrm{Co}_{52.4} \mathrm{Ni}_{22} \mathrm{Ga}_{25.6}$ and $\mathrm{Co}_{52.1} \mathrm{Ni}_{26.1} \mathrm{Ga}_{21.8}$ ribbons. These temperature ranges agree with those expected from the measurement of the coercive force and the observation of martensite

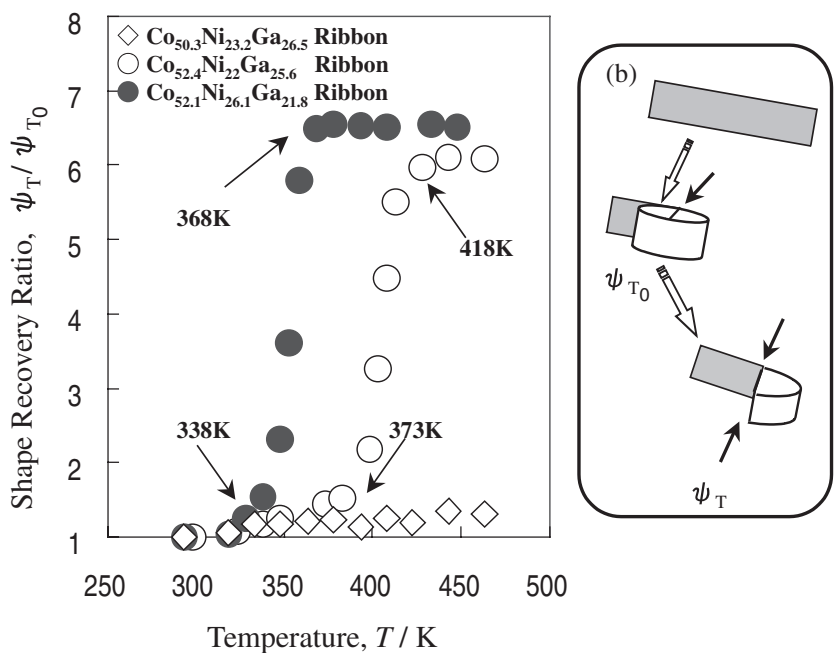

Fig. 9 (a) Temperature dependence of shape recovery of the $\mathrm{Co}_{2} \mathrm{NiGa}$ system ribbon, and (b) measurement technique. 
Table 2 Reverse transformation temperatures of the $\mathrm{Co}_{2} \mathrm{NiGa}$ system ribbon samples.

\begin{tabular}{ccccc}
\hline & \multicolumn{2}{c}{$\mathrm{Co}_{52.4} \mathrm{Ni}_{22} \mathrm{Ga}_{25.6}$} & \multicolumn{2}{c}{$\mathrm{Co}_{52.1} \mathrm{Ni}_{26.1} \mathrm{Ga}_{21.8}$} \\
\cline { 2 - 5 } & \multicolumn{1}{c}{$A_{\mathrm{s}}$} & $A_{\mathrm{f}}$ & $A_{\mathrm{s}}$ & $A_{\mathrm{f}}$ \\
\hline $\begin{array}{c}\text { Surface } \\
\text { observation }\end{array}$ & $368 \mathrm{~K}$ & $393 \mathrm{~K}$ & $328 \mathrm{~K}$ & $356 \mathrm{~K}$ \\
\hline $\begin{array}{c}\text { Magnetic } \\
\text { property }\end{array}$ & $350 \mathrm{~K}$ & $410 \mathrm{~K}$ & $333 \mathrm{~K}$ & $373 \mathrm{~K}$ \\
\hline Shape recovery & $373 \mathrm{~K}$ & $418 \mathrm{~K}$ & $338 \mathrm{~K}$ & $368 \mathrm{~K}$ \\
\hline
\end{tabular}

stripe-pattern. We found that $A_{\mathrm{s}}$ and the austenite-phase finishing temperature $A_{\mathrm{f}}$ are about $360 \mathrm{~K}$ and $410 \mathrm{~K}$, respectively, for $\mathrm{Co}_{52.4} \mathrm{Ni}_{22} \mathrm{Ga}_{25.6}$ ribbon sample, and about $330 \mathrm{~K}$ and $370 \mathrm{~K}$, respectively, for $\mathrm{Co}_{52.1} \mathrm{Ni}_{26.1} \mathrm{Ga}_{21.8}$ ribbon sample. For $\mathrm{Co}_{50.3} \mathrm{Ni}_{23.2} \mathrm{Ga}_{26.5}$ ribbon, the ratio does not change in the temperature range of this measurement. The results of measurement are listed in Table 2.

\section{Conclusions}

In this study, we examined a possibility of $\mathrm{Co}_{2} \mathrm{NiGa}$ system alloys as new FSMAs, when preparing the ribbon samples by using rapid-solidification melt-spinning method. The texture of ribbons was investigated by XRD and laser microscope. Magnetic property, strain induced by magnetic field and shape recovery were also measured. The main conclusions are as follows:

(1) The ribbons consist of the texture having a fine columnar grains.

(2) The magnetostriction for the $\mathrm{Co}_{52.4} \mathrm{Ni}_{22} \mathrm{Ga}_{25.6}$ ribbon is over $100 \times 10^{-6}$, which is 3.5 times larger than that of bulk sample having no texture.
(3) Shape recovery occurs in the temperature range from $A_{\mathrm{s}}$ to $A_{\mathrm{f}}$ for $\mathrm{Co}_{52.4} \mathrm{Ni}_{22} \mathrm{Ga}_{25.6}$ and $\mathrm{Co}_{52.1} \mathrm{Ni}_{26.1} \mathrm{Ga}_{21.8}$.

(4) The reverse transformation temperatures, $A_{\mathrm{s}}$ and $A_{\mathrm{f}}$, obtained from laser microscopic, coercive force and shape recovery observations are about $360 \mathrm{~K}$ and $410 \mathrm{~K}$ for $\mathrm{Co}_{52.4} \mathrm{Ni}_{22} \mathrm{Ga}_{25.6}$ and $330 \mathrm{~K}$ and $365 \mathrm{~K}$ for $\mathrm{Co}_{52.1} \mathrm{Ni}_{26.1} \mathrm{Ga}_{21.8}$.

(5) The $\mathrm{Co}_{2} \mathrm{NiGa}$ system alloy has better ductility, compared to the $\mathrm{Ni}_{2} \mathrm{MnGa}$ system alloy.

(6) From these results, we conclude that the $\mathrm{Co}_{2} \mathrm{NiGa}$ system alloy is a promising ferromagnetic shape memory alloy.

\section{Acknowledgements}

The authors are grateful to Prof. Masatoshi Shiba of Faculty of Science and Technology of Hirosaki University for his support of composition analysis.

\section{REFERENCES}

1) S. J. Murray, M. Marioni, S. M. Allen and R. C. O’Handley: Appl. Phys. Lett. 77 (2000) 886-888.

2) J. Koeda, Y. Nakamura, T. Fukuda, T. Kakeshita, T. Takeuchi and K. Kishio: Trans. Mater. Res. Soc. Jpn. 26 (2001) 215-217.

3) T. Kakeshita, T. Takeuchi, T. Fukuda, M. Tsujiguchi, T. Saburi, R. Oshima and S. Muto: Appl. Phys. Lett. 77 (2000) 1502-1504.

4) Y. Furuya, N. W. Hagood, H. Kimura and T. Watanabe: Mater. Trans., JIM 39 (1998) 1248-1254.

5) K. Tsuchiya, A. Ohashi, D. Ohtoyo, H. Nakayama, M. Umemoto and Paul G. McCormick: Mater. Trans., JIM 41 (2000) 938-942.

6) M. Wuttig, J. Li and C. Craciunescu: Scr. Metall. Mater. 44 (2001) 2393-2397.

7) K. Oikawa, T. Ota, F. Gejima, T. Ohmori, R. Kainua and K. Ishida: Mater. Trans., JIM 42 (2001) 2472-2475. 